\title{
Land Use Analysis in Thailand through GIS
}

\author{
Supan Karnchanasutham
}

Dean of Faculty of Geoinformatics, Burapha University, Chon Buri, Thailand

\begin{abstract}
Activities of remote sensing for land use in Thailand were initiated in 1975, in the field of Area Sampling Frame (ASF) to estimate the area, yield, production, and related information for "major rice" (rainy season rice) along with ground truth data for remote sensing research, i.e. training samples for image processing. In 1984, forecasting of the planted area and crop production and related information about economic crops using satellite data both at optical and microwave levels began.
\end{abstract}

Keywords: Land USE, GIS, Research

\section{Introduction}

Applications of GIS were initiated in 1990, with a view to mapping the area suitable for the planting of economic crops in Thailand on a scale of 1:250,000 using remote sensing and Geographic Information System (GIS). The area was derived from the overlay of data 312 soil series and thirty nine years of average rainfall as well as irrigation for 4 suitability classes, namely, highly suitable, moderately suitable, marginally suitable and unsuitable, in the main 25 watershed areas of Thailand. This map will enable to delineate forest conservation areas from legal forest use boundary areas, and built-up areas from other land use areas. All these will overlay administrative boundaries such as provincial boundaries, district and sub-district boundaries, along with main road networks. The results will provide suitability maps for the area planted with crops of economic importance in Thailand along with the determination of high suitability, moderate suitability, marginal suitability, and unsuitability classes, existing forest areas, deforested areas, water and builtup areas. The area of each class should conform to the administrative boundaries of the 76 provinces in Thailand (total area of 51.20 million hectares)

\section{Land use Analysis}

Thailand is considered an agricultural country. The country's economy relies heavily on agricultural products. Therefore, a timely and accurate statistical analysis of agricultural production is needed. Besides the conventional agricultural surveys, from which planted areas and production are estimated crop forecasting is also carried out every month before the release of survey results. Several approaches are employed and attempted as follows.

\subsection{Area Sampling Frame (AFS)}

The concept of AFS is to divide the total area to be surveyed into small blocks without any overlap or omission. ASF construction in Thailand has been used to estimate paddy area requires 3 strata to be constructed. Stratum 10 was sampled as representative of paddy land, stratum 20 as representative of uplands and stratum 23 as representative of deforested land. The topographic maps, at scales of 1:50,000 were used to subdivide the strata into Primary Sampling Units (PSUs) and Secondary Sampling Units (SSUs). Aerial photographs were ordered for selected SSUs to further subdivide SSUs into Sampling Units (SUs). Often three or four 1:15,000 scale photos were needed to cover the SSU. A total of 5,000 scale photos were needed for sampling the ASF sample. Once the SSUs were subdivided into SUs, the sampling units that were selected for each stratum in the frame call Segment, a photograph at scale of 1:5,000 was ordered for field work. The boundaries were marked on the photos and these became a part of the interviewing materials as well as part of the AFS frame. Interviews collected data from fields and farms inside segments. The size of a segment is about 80 Acres.

This technique, however, meant that segment boundaries on aerial photos were difficult to find or even nonexistent in the field if the land use had changed, because aerial photo taken from the Royal Thai Survey are out of date and need a lot of experienced staff 
to carry out. Thus, at present, this approach is not use.

\subsection{Loist Frame Sampling (LFS)}

This was employed in the crop surveys mostly where stratified two-stage sampling was required. Each village which reported having the crop under survey was stratified into 3-4 strata according to the reported croup acreages. Sample villages were randomly drawn from each stratum. About 10-20 crop growers in each sample village were selected randomly for interviews in order to estimate of the total area and characteristics under study obtained from this sample.

\subsection{Crop Forecasting}

Thailand is an agricultural exporting country for which export policy has to be formulated by crop forecasting, and this is an alternative to obtain this information at an early stage.

There are two different crop forecast techniques used for crop forecasting.

\subsubsection{Econometric Model}

In general this approach is divided into two models - the acreage model and the yield model. Presently there are 12 crops included in the monthly forecast for each province. For the mid-year outlook there are 65 commodities included in the national aggregate model. The acreage model uses the planted area of relevant crops specified as a function of the previous year's price, lagged prices of competing crops, and its own lagged area. For rice, amount and distribution of rainfall during the growing period is also considered to be an important variable in the planted area forecast model. For the yield model of early forecast, the average of historic yields for 3-5 years (excluding abnormal years due to drought, flood, disease and pests) is used. In later months, the rainfall and other inputs, such as fertilizers applied, are used in the forecasting yield model. This production forecast is obtained by multiply the acreage model with the yield model.

\subsubsection{Yield Component Model}

For certain crops such as rice, corn and soybeans, a yield component model is used in forecasting yield. In this approach, fields and plots of the concerned crop were randomly selected and the measurement of certain characteristics which were deemed related to the final yield of the crops, were recorded during the growing period up until harvest. These measurements were used as the independent variables, while the yield obtained from crop plots was used as the dependent variable in the model. Regression models were developed and the coefficients were estimated separately for each stage of crop growth. It is called a yield component model because the yield forecast is obtained form two separated yield component models. For example, the corn yield forecast is derived from the multiplication of number of ears harvested, and grain weight per ear forecasts. It is also called the objective yield survey since it involved surveys which used objective measurements of yield and related characteristics in the simple plot. This technique is very expensive and time-consuming and requires a lot of experienced staff to carry out. Thus, at present, this approach is adopted at a limited scale.

\subsection{Remote Sensing Technique}

Thailand has more than ten years of experience in utilizing remote sensing techniques in classification and estimation of crop acreage. However, it has mostly been estimation of dry season paddy which was carried out. In general, the results of this technique as compared with other estimations were satisfactory. Nevertheless, several problems remain to be solved. The first and important problem is cloud cover during the growing season when the information is needed. To cover the whole area, estimation and some random sampling techniques may be utilized. This technique, however, can give only a crop statistic or figure, not any geographic type of information. The other problem is the lack of equipment which is very expensive. Consequently, analysis of remotelysensed data cannot be accomplished soon enough to be used for the early warning system. Furthermore, the images and digital images are very expensive to study for temporal change or to monitor crop production since many different images recorded on different dates have to be ordered.

\subsection{Land use}

Land use or land utilization in Thailand is classified into regions and provinces by integrating every approach mentioned above and divided in 10 classes: forest land, paddy land, field crops, fruit trees, vegetables, grassland, other land and unclassified land. The total for each region or province is derived from the Royal Thai Survey. 


\section{Geographic Information System (GIS)}

Rice has been the most important economic crop in terms of both domestic consumption and export. Thailand is ranked first among the world's rice exporters with an income of hundreds of millions of baht. However, rice yield has still been as low as $60 \mathrm{~kg}$./hectare. Especially when compared with rice yield of various countries, Thailand is found to be in the lowest group. It is lower than that of Laos, Myanmar, Indonesia and China. Rice production has also caused a rapid decrease in forest area.

Nowadays, it is necessary to improve the yield because the area of rice can not be further expanded into the forests. However, the yield has still not much improved due to the unsuitability of the area for rice cultivation, both in physical and economic terms. Geographic Information Systems, the integration between spatial and attribute data, may eventually lead to agro-economic zoning in the future. The objectives are to produce maps of rice suitability with respect to the physical potential of the area. Those maps will lead to agro-economic zoning in the future.

\subsection{Methodology}

\subsubsection{Data conversion}

Data conversion from existing maps into digital format needs to be achieved by compiling such maps from relevant agencies. In some cases, thematic maps are not available or obsolete, so up-to-date maps are required. The converted relevant maps include:

3.1.1.1 Watershed areas are an area where the rainfall drains into one watershed. Classification and nomination is undertaken based on the respective main stream, except in coastal areas and the area near the Cambodian border where main streams do not exist. Watershed classification and nomination is therefore based on geographic location such as the eastern coast, west, south and southwest.

Watershed area allocation is achieved by defining the derivatives the 1:50,000 topographic maps. Thailand comprises a total of 25 main watersheds, each of which includes 4 levels of stream:

1) main stream

2) sub-stream

3) perennial gully, and

4) seasonal gully
3.1.1.2. Provincial soil series maps, at a scale of 1:50,000 which comprises 312 soil series for the whole country.

3.1.1.3. Irrigation maps comprise both irrigation and non-irrigation zones.

3.1.1.4. Average rainfall map of 39 years from 1951 to 1989 obtained from the Department of Meteorology for which average rainfall is classified into 10 levels.

3.1.1.5. Legal forest boundary maps, at a scale of 1:250,000 which includes both inland forests and mangrove forest boundaries. Inland forests are categorized into 2 zones: economic forests and conserved forests.

3.1.1.6. Road network map, at a scale of $1: 1,000,000$ and 1:250,000. Road maps comprise highways with route numbers, provincial roads with route numbers, etc.

3.1.1.7. Administrative boundary maps, at a scale of 1:250,000 including: Province boundaries, District boundaries, and Subdistrict boundaries. The information obtained in 2009 comprises 76 provinces, 812 district, 7,409 sub-district and 68,700 villages.

3.1.1.8. Present land use map, at a scale of 1:250,000, including 30 categories.

\subsection{Data Analysis}

Data analysis was carried out using TNT, MIPS and ORACLE software steps are follows: 3.2.1.Project construction and database establishment to integrate spatial information, obtained from digital maps, and attributed information such as topology.

3.2.2.Data analysis was undertaken by overlaying of multilayer spatial information. The data includes:

3.2.2.1. Soil series were categorized, in accordance with suitability of conditions, into 4 levels namely:

1) high suitability for rice cultivation

2) moderate suitability for rice cultivation

3) marginal suitability for rice cultivation

4) unsuitability for rice cultivation

3.2.2.2. The rainfall map was categorized into 4 levels namely:

- Rainfall of 1,100 - 1,400 mm. of high suitability for rice.

- Rainfall of 1,100 - 1,100 mm. and 1,400 $1,600 \mathrm{~mm}$. of moderate suitability for rice.

- The rainfall of $1,600-2,000 \mathrm{~mm}$. of marginal suitability for rice.

- The rainfall of $2,000-5,000 \mathrm{~mm}$. of unsuitability for rice. 
3.2.2.3. Overlay of the rainfall map onto the irrigation zone and soil series maps obtained the map of suitable areas for rice cultivation.

3.2.2.4. The map of suitability for rice cultivation was then overlaid onto the present land use map and legal forest boundary map to exclude the undesirable areas including conserved forest, water bodies, and others.

3.2.2.5. Calculation of the suitability for rice cultivation was made for each province and district to cover the whole country.

\subsection{Results}

The results comprise 2 types of information: maps and levels of rice suitability in each watershed, which was classified into 8 levels. They are:
1) highly suitable areas
2) moderately suitable areas
3) marginally suitable areas
4) unsuitable areas

\section{References}

[1] A. Pongsrihadulchai. Agricultural Statistics in Thailand. Office of Agricultural Economics , Ministry of Agriculture and Cooperative, Bangkok, Thailand, 1996.

[2] A. Pongsrihadulchai S. Karnchanasutham and C . Rodprom. Rice Monitoring Using ERS-1 SAR Data in Kanchanaburi Province Thailand . ERS- 1 Project ( ALA/91/28), Bangkok, Thailand, 1996.

[3] Center for Agricultural Information. Agricultural Statistics of Thailand Crop Year 1996/1997 . Agricultural Economice , Bangkok, Thailand, 1998.

[4] S. Karnchanasutham. Using Remote Sensing and Geographic Information System for Agricultural Zoning. Dissertation, Asian Institute of Technology, Bangkok, Thailand, 1999. 